\title{
Reticular Chemistry at Its Best: Directed Assembly of Hexagonal Building Units into the Awaited Metal-Organic Framework with the Intricate Polybenzene Topology, pbz-MOF
}

Dalal Alezi, ${ }^{\dagger}$ Ioannis Spanopoulos, ${ }^{\ddagger}$ Constantinos Tsangarakis, ${ }^{\ddagger}$ Aleksander Shkurenko, ${ }^{\dagger}$ Karim Adil $^{\dagger}$ Youssef Belmabkhout, ${ }^{\dagger}$ Michael $\mathrm{O}^{\prime}$ Keeffe, ${ }^{\S}$ Mohamed Eddaoudi, ${ }^{*}{ }^{\dagger}$ and Pantelis N. Trikalitis ${ }^{*}, \neq$

${ }^{\ddagger}$ Department of Chemistry, University of Crete, Voutes 71003 Heraklion, Greece

${ }^{\dagger}$ Functional Materials Design, Discovery \& Development $\left(\mathrm{FMD}^{3}\right)$, Advanced Membranes \& Porous Materials Center, Division of Physical Sciences and Engineering, King Abdullah University of Science and Technology (KAUST), Thuwal 23955-6900, Kingdom of Saudi Arabia

${ }^{\S}$ School of Molecular Sciences, Arizona State University, Tempe, Arizona 85287, United States

Supporting Information

\begin{abstract}
The ability to direct the assembly of hexagonal building units offers great prospective to construct the awaited and looked-for hypothetical polybenzene ( $\mathbf{p b z})$ or "cubic graphite" structure, described 70 years ago. Here, we demonstrate the successful use of reticular chemistry as an appropriate strategy for the design and deliberate construction of a zirconium-based metal-organic framework (MOF) with the intricate $\mathbf{p b z}$ underlying net topology. The judicious selection of the perquisite hexagonal building units, six connected organic and inorganic building blocks, allowed the formation of the pbz-MOF-1, the first example of a $\mathrm{Zr}(\mathrm{IV})$-based MOF with pbz topology. Prominently, pbz-MOF-1 is highly porous, with associated pore size and pore volume of $13 \AA$ and $0.99 \mathrm{~cm}^{3} \mathrm{~g}^{-1}$, respectively, and offers high gravimetric and volumetric methane storage capacities $\left(0.23 \mathrm{~g} \mathrm{~g}^{-1}\right.$ and $210.4 \mathrm{~cm}^{3}$ (STP) $\mathrm{cm}^{-3}$ at $80 \mathrm{bar}$ ). Notably, the pbz-MOF1 pore system permits the attainment of one of the highest $\mathrm{CH}_{4}$ adsorbed phase density enhancements at high pressures $\left(0.15\right.$ and $0.21 \mathrm{~g} \mathrm{~cm}^{-3}$ at 35 and 65 bar, respectively) as compared to benchmark microporous MOFs.
\end{abstract}

M etal-organic frameworks (MOFs), a relatively new class of functional solid-state materials, have demonstrated impressive capabilities in various key applications such as gas storage/separation, catalysis, sensing, and drug release. ${ }^{1}$ The crystalline nature of MOFs makes this new generation of porous solids highly appealing due to the great prospective to correlate structure to property. The crystal structure information allows for the precise analysis of these materials and most importantly gaining insights on the connectivity of their basic building units. Indeed, the topology, defined as the underlying connectivity of a material, is nowadays of prime importance in MOF chemistry as it enables the successful practice of reticular chemistry and the subsequent construction of the targeted MOF with the desired structural features. ${ }^{2}$ It is to note that important topologies (enumerated/predicted or experimentally evidenced) are catalogued and available online in the Reticular Crystal Structure (RCSR) Database. ${ }^{3}$

The introduction of reticular chemistry has permitted to enlarge and enrich the discovery and the synthesis of functional solid-state materials in general and MOFs in particular. Its successful implementation relies on the combination of predesigned inorganic building units and organic linkers, taking into account both the resultant net underlying topology and the building units geometrical constrains. One way to achieve this goal is via the deployment of the molecular building block (MBB) approach for the design and synthesis of MOFs based on the reticulation of edge-transitive nets (nets with all edges related by symmetry) as blueprints. ${ }^{4}$ The viability of the MOF design depends on the availability of the organic and inorganic MBBs, and subsequently the design complexity increases proportionally depending on the requisite control of the MBBs connectivity and their vis-à-vis positioning. For simplicity we refer to the design complexity levels as level 1 when it is relatively simple and level 4 when it is intricate. For level 1, the basic level, the targeted MOF is mainly based on readily accessible building blocks and their subsequent connectivity with no specific requirement for their vis-a vis positioning; the common example is diamond topology which is the most abundant topology in MOF chemistry. ${ }^{4 a}$ For level 2, the medium level, a specific positioning of the building units is required, and an illustrative example is the nbo-MOFs. ${ }^{\text {la }}$ For level 3, the elaborate level, the limiting step is the ability to access highly connected building units, and illustrative examples are UiO-66 and fcu-MOFs. ${ }^{5}$ Level 4, the intricate level, requires the use of scarce and well-defined building units and their subsequent precise/particular positioning in order to achieve the targeted structure.

In this context, highly connected symmetrical metal clusters are of particular interest in targeting new fascinating MOFs, because of the limited number of possible nets that are compatible with their connectivity. ${ }^{6}$ Representative examples are the highly connected hexanuclear $\mathrm{Zr}-$, Hf-, and RE-based MBBs, which can be employed as a 12-, 10-, 8-, or even 6-

Received: August 9, 2016

Published: September 10, 2016 
connected secondary building units (SBUs). ${ }^{2 \mathrm{~d}, 7}$ Markedly, the 6connected $\mathrm{Zr}_{6}$ cluster, $\left[\mathrm{M}_{6}\left(\mu_{3}-\mathrm{O}\right)_{8-x}\left(\mu_{3}-\mathrm{OH}\right)_{x}\left(\mathrm{O}_{2} \mathrm{C}-\right)_{6}\right.$ $\left.\left(\mathrm{O}_{2} \mathrm{C}\right)_{6}\right]$, can express either a trigonal antiprism ${ }^{8}$ or a hexagonal planar SBU depending on the relative position of the 6-points of extension. ${ }^{7}$

Noticeably, the 6-connected $\mathrm{Zr}_{6}$ cluster, having the perfect $D_{6}$ symmetry and the points of extension matching the 6 vertices of a hexagonal planar SBU, is an ideal inorganic building unit to target the synthesis of MOFs with the intricate underlying 6-c hxg topology. Employing this topology as a blueprint to design MOF requires precise control of the positioning of the hexagonal building units, the intricate design level (level 4). This type of net can be found in the hypothetical structure of polybenzene (pbz) or "cubic graphite", ${ }^{10}$ first proposed by Gibson et al. in $1946^{11}$ and portrayed as a plausible very stable polymorph of threecoordinated $\left(\mathrm{sp}^{2}\right)$ carbon. In 1992, ${ }^{12}$ this structure was predicted to be by far more stable energetically than $\mathrm{C}_{60}$ and can be best viewed as aromatic $\mathrm{C}_{6}$ rings linked by single bonds (see Figure 1 ). Therefore, there is a great effort to synthesize this unique material as well as augmented analogues described with the general term, "polyphenylenes". ${ }^{15,18}$ a)

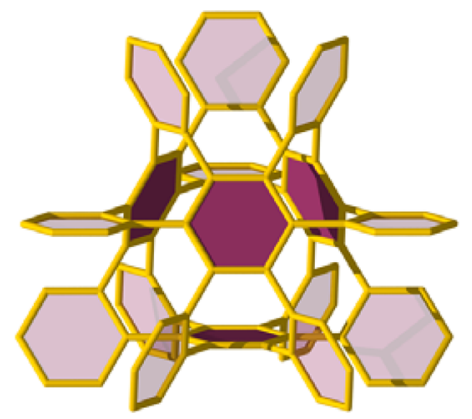

b)

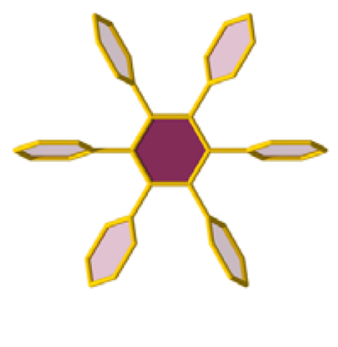

Figure 1. Part of the pbz structure emphasizing the tetrahedral cavities (a) and the connectivity of adjacent phenyl rings (b).

In MOF chemistry, the augmented hxg net (hxg-a and also referred to as pbz due to its interest in other contexts) has been described and presented as a very rare example of a structure that its construction would require a true design, where the dictated particular and directional information on the organic and inorganic building blocks will permit the assembly of this looked-for and specific predetermined structure, which is based on the only edge-transitive net for linking 6-c hexagonal building units. ${ }^{13}$ Valuably, the successful synthesis of this intricate pbzMOF will provide access to a topologically very distinct pore system, allowing its exploration in gas adsorption storage and gaining insights on the topology-property relationship. It is to note that the $\mathbf{h x g}$ topology has been observed in the case of $\mathrm{NH}_{4}\left[\mathrm{Cu}_{3}-\left(\mu_{3}-\mathrm{OH}\right)\left(\mu_{3} \text {-4-carboxypyrazolato }\right)_{3}\right],{ }^{14} \quad\left[\mathrm{Cu}_{3}\left(\mu_{3}-\right.\right.$ $\mathrm{OH})$-(4-pyridyltetrazolato $\left.)_{3}(\mathrm{OH})(\mathrm{DMF})_{4}\right]^{1,5}$ and NJUBai9, ${ }^{16}$ but these do not represent a pbz net as their basic organic and inorganic building units are not hexagons.

Here, we report the successful implementation of reticular chemistry, where the 6-c hexagonal zirconium cluster was used for the construction of a porous $\mathrm{Zr}$-MOF based on the edge transitive hxg net. To the best of our knowledge, this is the first report disclosing the assembly of the 6-c hexagonal $\mathrm{Zr}$ clusters with 6-c hexagonal organic linker into the default 6-c hxg-MOF, in which the augmented hxg net matches the pbz-net (polybenzene-type structure).
Fundamentally, as has been described previously ${ }^{12}$ and shown in Figure $1 \mathrm{~b}$, in the 3-periodic structure of $\mathbf{p b z}$, the dihedral angle between two phenyl rings is $70.5^{\circ}$, while the neighboring rings attached to the same ring have complementary dihedral angles of $70.5^{\circ}$ and $109.5^{\circ}$ (see Figure S9), resembling the blades in contra-rotating propellers. Careful structural analysis of the hexagonal $\mathrm{Zr}_{6}$ cluster and in view of the hexagon formed by the carbon atoms of the six equatorial carboxylate groups, a very similar propeller-like arrangement is observed, see Figure 2a.

a)
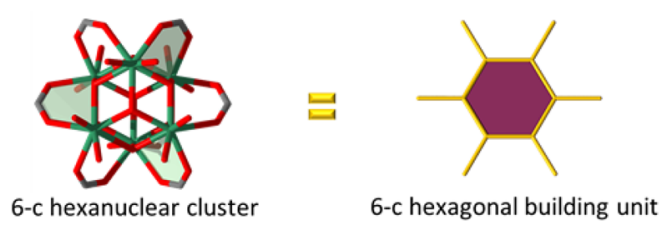

b)
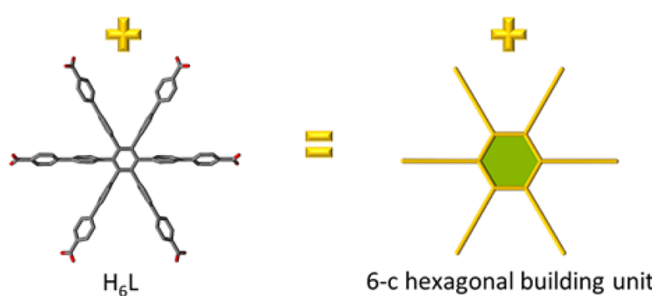

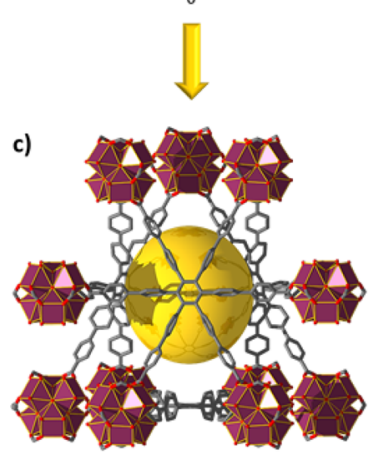

pbz-MOF-1
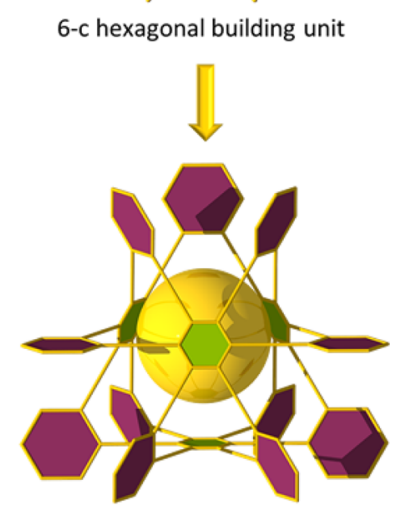

pbz-net (hxg-a)
Figure 2. Combination of $\mathrm{Zr}_{6}$ clusters (a), with the hexatopic $\mathrm{H}_{6} \mathrm{~L}$ ligand (b), both with hexagonal planar geometry, lead to the construction of pbz-MOF-1 (c), displaying the augment hxg-a net, original described in the structure of $\mathbf{p b z}$.

However, in this case the complementary dihedral angles are $49.6^{\circ}$ and $130.4^{\circ}$. These simple geometrical considerations infer that in order for the looked-for pbz-MOF to be materialized, using the hexagonal $\mathrm{Zr}_{6}$ cluster as the inorganic building unit, it is necessary to employ a hexagonal 6-connected carboxylate-based organic linker that will be able to provide and accommodate the additional twist in the dihedral angle and thus affords the $70.5^{\circ}$ found in the pbz type structure.

Based on this careful and insightful geometrical analysis, we designed and synthesized the rigid and nanosized hexatopic carboxylate-based organic ligand $\mathrm{H}_{6} \mathbf{L}$ (Figures $\mathrm{S} 1-\mathrm{S} 5$ ), depicted in Figure 2b. As anticipated, the solvothermal reaction of $\mathrm{H}_{6} \mathbf{L}$ with $\mathrm{ZrCl}_{4}$ in $N, N^{\prime}$-dimethylformamide (DMF) in the presence of acetic acid afforded colorless octahedral-like single crystals (Figure S6), suitable for structural determination. The resultant MOF, denoted here as pbz-MOF-1, crystallizes in the cubic system, space group $F d-3 m$ with a large unit cell, $a=44.856(2) \AA$, $V=90252(9) \AA^{3}$. The 3-periodic framework consists of $6-\mathrm{c} \mathrm{Zr}_{6}$ clusters linked by the fully deprotonated hexacarboxylate ligands $\mathrm{L}^{6-}$. The single crystal X-ray data (Table S1) show that each $\mathrm{Zr}_{6}$ 
cluster encompasses six crystallographically equivalent $\mu_{3}-\mathrm{O}^{2-}$ anions ( $\mathrm{Zr}-\mathrm{O} 3$ bond length, $2.133 \AA$ ), placed at the equatorial positions of the hexagon which are located $0.682(6) \AA$ above the plane containing the three $\mathrm{Zr}$ atoms. In addition, there are two crystallographically equivalent $\mu_{3}-\mathrm{OH}^{-}$anions $(\mathrm{Zr}-\mathrm{O} 2$ bond length, $2.187 \AA$ ) at the faces of the hexagon, placed 0.840 (1) $\AA$ above the plane of the adjacent, three $\mathrm{Zr}$ atoms. Interestingly, the observed chemical formula, $\left[\mathrm{Zr}_{6}\left(\mu_{3}-\mathrm{O}\right)_{6}\left(\mu_{3}-\mathrm{OH}\right)_{2}\right]^{10+}$, representing the $\mathrm{Zr}_{6}$ core, is different from the previously reported hexagonal $\mathrm{Zr}_{6}$ clusters, formulated as $\left[\mathrm{Zr}_{6}\left(\mu_{3}-\mathrm{OH}\right)_{8}\right]^{16+}(\mathrm{PCN}$ $224),{ }^{9 \mathrm{a}}\left[\mathrm{Zr}_{6}\left(\mu_{3}-\mathrm{O}\right)_{4}\left(\mu_{3}-\mathrm{OH}\right)_{4}\right]^{12+},{ }^{12}$ and $\left[\mathrm{Zr}_{6}\left(\mu_{3}\right.\right.$ $\left.\mathrm{O})_{8}(\mathrm{OH})_{2}\left(\mathrm{H}_{2} \mathrm{O}\right)_{10}\right]^{6+}$. ${ }^{\mathrm{c}}$ The $\mathrm{Zr}$ atoms at the faces of the $\mathrm{Zr}_{6}$ hexagon complete their coordination sphere with acetate anions (Ac), $\mathrm{OH}^{-}$, and $\mathrm{H}_{2} \mathrm{O}$ species. ${ }^{1} \mathrm{H}$ NMR measurements in acetone exchanged samples, digested with $\mathrm{NaOH}$, showed that the Ac: $\mathrm{L}$ ratio is 5 (see Figure S12). Accordingly, the proposed charge balanced chemical formula for the pbz-MOF-1 is $\left[\mathrm{Zr}_{6}\left(\mu_{3}\right.\right.$ $\left.\mathrm{O})_{6}\left(\mu_{3}-\mathrm{OH}\right)_{2}(\mathrm{Ac})_{5}(\mathrm{OH})\left(\mathrm{H}_{2} \mathrm{O}\right)\right] \mathbf{L}$. The formula is also confirmed by thermogravimetric (TGA) and elemental analysis.

Further structural analysis of the pbz-MOF-1 revealed that the observed dihedral angle between the central phenyl ring of the organic linker and the hexagonal plane of the $\mathrm{Zr}_{6}$ cluster is $70.53^{\circ}$ (see Figure S9), as expected and imposed by this topology. In point of fact, given that there are no preassembled $\mathrm{Zr}_{6}$ clusters as a starting entity in the initial reaction mixture, it is conceivable to regard the organic ligand as a directing-cluster agent and a template for the in situ formation of these 6-c clusters, prompted by the suitable geometrical features of the ligand favoring the assembly of the stable pbz-MOF, a highly symmetric cubic lattice.

The phase purity of pbz-MOF-1 was confirmed by comparison of the powder X-ray diffraction (PXRD) patterns. The compound was found to be stable in common organic solvents including acetonitrile and acetone (Figure S7).

As shown in Figure 2c, the structure of pbz-MOF-1 contains tetrahedral cavities of $\sim 13 \AA$ in diameter, delimited by four organic linkers, occupying the faces of the tetrahedron, and 12 $\mathrm{Zr}_{6}$ clusters. These cavities are interconnected through triangular-like windows and smaller cavities of $\sim 6.5$ and $9.5 \AA$, respectively, running along the [110] crystallographic direction (Figures S10, S11). The corresponding solvent-accessible volume in the pbz-MOF-1, calculated using the PLATON software, ${ }^{17}$ is estimated to be $69 \%$. Looking along the [100] crystallographic direction, the distance between opposite $\mathrm{Zr}_{6}$ clusters is $\sim 3.8 \AA$, measured from the methyl carbon atoms of the coordinate acetate anions and without taking into account the hydrogen atoms. Therefore, it is highly likely that the size of the hexagonal ligand in the pbz-MOF-1 represents a size cutoff for this type of linkers, below which the pbz net cannot be formed due to steric effects.

Argon adsorption isotherm recorded at $87 \mathrm{~K}$ confirmed the permanent porosity of pbz-MOF-1, showing a fully reversible type-I isotherm characteristic of a microporous material, see Figure 3a. The apparent BET (Langmuir) surface area, estimated using the pressure range $0.0065-0.0051 \mathrm{P} / \mathrm{P}_{\mathrm{o}}$ (seven points), was estimated to be $2415 \mathrm{~m}^{2} \mathrm{~g}^{-1}\left(2556 \mathrm{~m}^{2} \mathrm{~g}^{-1}\right)$, in excellent agreement with the calculated BET surface area, $2432 \mathrm{~m}^{2} \mathrm{~g}^{-1}$, obtained by Poreblazer. ${ }^{18}$ The pore volume, calculated at $0.95 \mathrm{P} /$ $P_{o}$ is $0.99 \mathrm{~cm}^{3} \mathrm{~g}^{-1}$, is in excellent agreement with the crytallographically determined value of $1.0 \mathrm{~cm}^{3} \mathrm{~g}^{-1}$. In addition to gas adsorption results, the structural integrity of the activated pbz-MOF-1 was supported by PXRD measurements (Figure S7). The pore size distribution was calculated from the Ar a
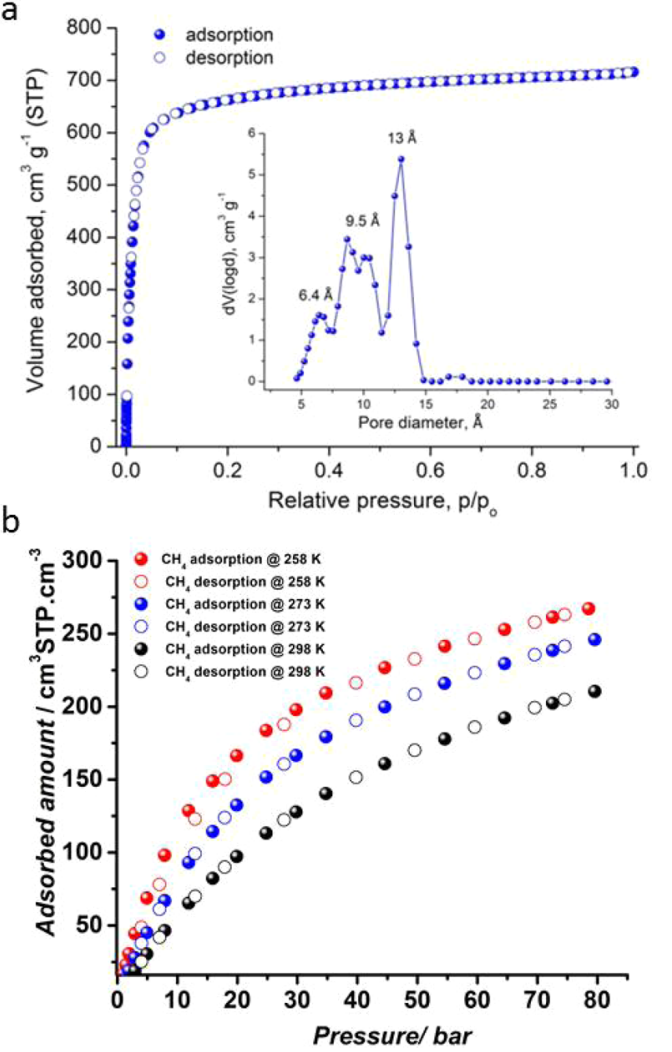

Figure 3. (a) Argon sorption isotherm of pbz-MOF-1 recorded at $87 \mathrm{~K}$ and the corresponding pore size distribution curve calculated using NLDFT (inset). (b) $\mathrm{CH}_{4}$ sorption isotherms of pbz-MOF-1 at 298, 273, and $258 \mathrm{~K}$, up to $80 \mathrm{bar}$.

adsorption isotherm using NLDFT, revealing three distinct peaks centered at 13, 9.5, and $6.4 \AA$ (inset in Figure 3a), in full agreement with the crystallographic analysis.

In light of its interesting structural features containing a high density of phenyl rings per accessible volume $\left(2.3\right.$ per $\left.\mathrm{nm}^{3}\right)$, combined with a well-defined micropore system and high BET surface area $\left(2415 \mathrm{~m}^{2} \mathrm{~g}^{-1}\right)$, pbz-MOF-1 may be considered as an excellent adsorbent candidate for gas storage applications and in particular for $\mathrm{CH}_{4}$. Accordingly, $\mathrm{CH}_{4}$ adsorption measurements at $112 \mathrm{~K}$, revealed a reversible type-I isotherm (Figure S13), from which the total pore volume at $0.99 \mathrm{P} / \mathrm{P}_{\mathrm{o}}$ was calculated to be $0.95 \mathrm{~cm}^{3} \mathrm{~g}^{-1}$, indicating that the full available pore space in the pbz-MOF-1 is readily accessible by $\mathrm{CH}_{4}$ molecules. Highpressure $\mathrm{CH}_{4}$ adsorption measurements were carried out at different temperatures up to 80 bar (Figure 3b). The observed gravimetric and volumetric uptake at 80 bar and $298 \mathrm{~K}$ is $0.23 \mathrm{~g}$ $\mathrm{g}^{-1}$ and $210.4 \mathrm{~cm}^{3}$ (STP) $\mathrm{cm}^{-3}$, placing pbz-MOF-1 among the high-performing MOFs for $\mathrm{CH}_{4}$ storage (Table S2 and Figure S14). The corresponding $\mathrm{CH}_{4}$ capacities at 273 and $258 \mathrm{~K}$ are $0.27 \mathrm{~g} \mathrm{~g}^{-1} / 246 \mathrm{~cm}^{3} \mathrm{~cm}^{-3}$ and $0.29 \mathrm{~g} \mathrm{~g}^{-1} / 267 \mathrm{~cm}^{3} \mathrm{~cm}^{-3}$, respectively. Further analysis of the adsorption uptakes at different pressures and room temperature showed that pbzMOF-1 exhibits one of the largest increases in the $\mathrm{CH}_{4}$ adsorbed phase density between 35 and 65 bar (38.3\%), as compared to other well-performing MOFs for $\mathrm{CH}_{4}$ storage (Table S3 and Figure S15). Reasonably, this enhanced $\mathrm{CH}_{4}$ density in the pbzMOF-1 could be associated with the favorable and very high efficiency in filling the available space in the pore network. Equivalent values for other existing MOFs such as HKUST-1 (17.4\%), ${ }^{19}$ Al-soc-MOF-1 (62.8\%), ${ }^{20}$ PCN-14 (16.6\%), ${ }^{21}$ MOF- 
$520(38.7 \%),{ }^{22}$ and MOF-905 (44.6\%) ${ }^{23}$ supports and affirms the high degree of $\mathrm{CH}_{4}$ packing in the pbz-MOF-1 between 35 and 65 bar. The gravimetric and volumetric working capacity between 5 and 80 bar and $298 \mathrm{~K}$ is estimated to be $22.7 \mathrm{wt} \%$ and $180 \mathrm{~cm}^{3} \mathrm{~cm}^{-3}$, respectively. Interestingly, in contrast to other MOFs with intermediate porosity such as PCN-14, ${ }^{21}$ HKUST$1,{ }^{19} \mathrm{Ni}-\mathrm{MOF}-74,{ }^{19}$ and UTSA-20, ${ }^{24}$ the decrease of the storage temperature to $273 \mathrm{~K}$ led to an increase in the $\mathrm{CH}_{4}$ working capacity. For instance, in the case HKUST-1 and when going from 298 to $273 \mathrm{~K}$, the volumetric working capacity between 5 and 65 bar decreased from 190 to $155 \mathrm{~cm}^{3} \mathrm{~cm}^{-3}$. Whereas for pbz-MOF-1, under the same conditions, the opposite occurred, and an increase from 162 to $185 \mathrm{~cm}^{3} \mathrm{~cm}^{-3}$ was observed. This manifest unique feature in the microporous pbz-MOF-1 could be attributed to the favorable synergistic effect between the pore system dimensions and the localized high density of aromatic rings per accessible unit volume.

In summary, we have demonstrated for the first time the successful use of reticular chemistry and the MMB approach for the construction of a highly connected $\mathrm{Zr}$-based MOF with the intricate pbz topology. The synthesis of the pbz-MOF-1 represents the first example of a crystalline solid-state material displaying the binary 6-c hxg-a net, matching the unique edgetransitive pbz net. High-pressure $\mathrm{CH}_{4}$ adsorption measurements on the highly porous pbz-MOF-1 revealed a high storage capacity of $0.23 \mathrm{~g} \mathrm{~g}^{-1}$ and $210.4 \mathrm{~cm}^{3}$ (STP) $\mathrm{cm}^{-3}$ at 80 bar. Moreover, pbz-MOF-1 exhibits one of the highest enhancements in the adsorbed phase density when going from 35 to 65 bar. The successful synthesis of the first pbz-MOF paves the way to expand this approach to other ligands and inorganic building blocks with the aim to tune the pore system and functionality.

\section{ASSOCIATED CONTENT}

\section{S Supporting Information}

The Supporting Information is available free of charge on the ACS Publications website at DOI: 10.1021/jacs.6b08176.

Synthesis, NMR, PXRD, TGA, and additional sorption data (PDF)

Crystallographic data (CIF)

\section{AUTHOR INFORMATION}

\section{Corresponding Authors}

*ptrikal@uoc.gr

*mohamed.eddaoudi@kaust.edu.sa

\section{Notes}

The authors declare no competing financial interest.

\section{ACKNOWLEDGMENTS}

This research has been cofinanced by the European Union and Greek national funds through the Operational Program "Education and Lifelong Learning" of the National Strategic Reference Framework, Research Funding Program: ARISTEIA II - 4862. Financial support by King Abdullah University of Science and Technology is gratefully acknowledged.

\section{REFERENCES}

(1) (a) Eddaoudi, M.; Kim, J.; Rosi, N.; Vodak, D.; Wachter, J.; O’Keeffe, M.; Yaghi, O. M. Science 2002, 295, 469. (b) Kitagawa, S.; Kitaura, R.; Noro, S. Angew. Chem., Int.Ed. 2004, 43, 2334. (c) Furukawa, H.; Cordova, K. E.; O’Keeffe, M.; Yaghi, O. M. Science 2013, 341, 1230444.
(2) (a) Yaghi, O. M.; O’Keeffe, M.; Ockwig, N. W.; Chae, H. K.; Eddaoudi, M.; Kim, J. Nature 2003, 423, 705. (b) O'Keeffe, M.; Yaghi, O. M. Chem. Rev. 2012, 112, 675. (c) Li, M.; Li, D.; O'Keeffe, M.; Yaghi, O. M. Chem. Rev. 2014, 114, 1343. (d) Luebke, R.; Belmabkhout, Y.; Weselinski, L. J.; Cairns, A. J.; Alkordi, M.; Norton, G.; Wojtas, L.; Adil, K.; Eddaoudi, M. Chem. Sci. 2015, 6, 4095. (e) Catarineu, N. R.; Schoedel, A.; Urban, P.; Morla, M. B.; Trickett, C. A.; Yaghi, O. M. J. Am. Chem. Soc. 2016, 138, 10826. (f) Qin, J.-S.; Du, D.-Y.; Li, M.; Lian, X.-Z.; Dong, L.-Z.; Bosch, M.; Su, Z.-M.; Zhang, Q.; Li, S.-L.; Lan, Y.-Q.; Yuan, S.; Zhou, H.-C. J. Am. Chem. Soc. 2016, 138, 5299.

(3) O’Keeffe, M.; Peskov, M. A.; Ramsden, S. J.; Yaghi, O. M. Acc. Chem. Res. 2008, 41, 1782.

(4) (a) Eddaoudi, M.; Moler, D. B.; Li, H. L.; Chen, B. L.; Reineke, T. M.; O’Keeffe, M.; Yaghi, O. M. Acc. Chem. Res. 2001, 34, 319. (b) Eddaoudi, M.; Sava, D. F.; Eubank, J. F.; Adil, K.; Guillerm, V. Chem. Soc. Rev. 2015, 44, 228.

(5) (a) Cavka, J. H.; Jakobsen, S.; Olsbye, U.; Guillou, N.; Lamberti, C.; Bordiga, S.; Lillerud, K. P. J. Am. Chem. Soc. 2008, 130, 13850. (b) Xue, D. X.; Cairns, A. J.; Belmabkhout, Y.; Wojtas, L.; Liu, Y. L.; Alkordi, M. H.; Eddaoudi, M. J. Am. Chem. Soc. 2013, 135, 7660.

(6) (a) Guillerm, V.; Weselinski, L. J.; Belmabkhout, Y.; Cairns, A. J.; D’Elia, V.; Wojtas, L.; Adil, K.; Eddaoudi, M. Nat. Chem. 2014, 6, 673. (b) Alezi, D.; Peedikakkal, A. M. P.; Weselinski, L. J.; Guillerm, V.; Belmabkhout, Y.; Cairns, A. J.; Chen, Z.; Wojtas, L.; Eddaoudi, M. J. Am. Chem. Soc. 2015, 137, 5421.

(7) Bai, Y.; Dou, Y.; Xie, L.-H.; Rutledge, W.; Li, J.-R.; Zhou, H.-C. Chem. Soc. Rev. 2016, 45, 2327.

(8) (a) Furukawa, H.; Gandara, F.; Zhang, Y.-B.; Jiang, J.; Queen, W. L.; Hudson, M. R.; Yaghi, O. M. J. Am. Chem. Soc. 2014, 136, 4369. (b) Feng, D.; Wang, K.; Su, J.; Liu, T.-F.; Park, J.; Wei, Z.; Bosch, M.; Yakovenko, A.; Zou, X.; Zhou, H.-C. Angew. Chem., Int. Ed. 2015, 54, 149.

(9) (a) Feng, D.; Chung, W.-C.; Wei, Z.; Gu, Z.-Y.; Jiang, H.-L.; Chen, Y.-P.; Darensbourg, D. J.; Zhou, H.-C. J. Am. Chem. Soc. 2013, 135, 17105. (b) Wang, R.; Wang, Z.; Xu, Y.; Dai, F.; Zhang, L.; Sun, D. Inorg. Chem. 2014, 53, 7086. (c) Cui, H.; Wang, Y.; Wang, Y.; Fan, Y.-Z.; Zhang, L.; Su, C.-Y. CrystEngComm 2016, 18, 2203.

(10) Shen, X. F.; Ho, D. M.; Pascal, R. A. Org. Lett. 2003, 5, 369.

(11) Gibson, J.; Holohan, M.; Riley, H. L. J. Chem. Soc. 1946, 456.

(12) O'keeffe, M.; Adams, G. B.; Sankey, O. F. Phys. Rev. Lett. 1992, 68, 2325.

(13) (a) Friedrichs, O. D.; O'Keeffe, M. O.; Yaghi, O. M. Acta Crystallogr., Sect. A: Found. Crystallogr. 2003, 59, 515. (b) Ockwig, N. W.; Delgado-Friedrichs, O.; O'Keeffe, M.; Yaghi, O. M. Acc. Chem. Res. 2005, 38, 176.

(14) Procopio, E. Q.; Linares, F.; Montoro, C.; Colombo, V.; Maspero, A.; Barea, E.; Navarro, J. A. R. Angew. Chem., Int. Ed. 2010, 49, 7308.

(15) Ouellette, W.; Liu, H. X.; O’Connor, C. J.; Zubieta, J. Inorg. Chem. 2009, 48, 4655.

(16) Yun, R. R.; Lu, Z. Y.; Pan, Y.; You, X. Z.; Bai, J. F. Angew. Chem., Int. Ed. 2013, 52, 11282 .

(17) Spek, A. L. Acta Crystallogr., Sect. D: Biol. Crystallogr. 2009, 65, 148 .

(18) Sarkisov, L.; Harrison, A. Mol. Simul. 2011, 37, 1248.

(19) Peng, Y.; Krungleviciute, V.; Eryazici, I.; Hupp, J. T.; Farha, O. K.; Yildirim, T. J. Am. Chem. Soc. 2013, 135, 11887.

(20) Alezi, D.; Belmabkhout, Y.; Suyetin, M.; Bhatt, P. M.; Weselinski, L. J.; Solovyeva, V.; Adil, K.; Spanopoulos, I.; Trikalitis, P. N.; Emwas, A.H.; Eddaoudi, M. J. Am. Chem. Soc. 2015, 137, 13308.

(21) Mason, J. A.; Veenstra, M.; Long, J. R. Chem. Sci. 2014, 5, 32.

(22) Gandara, F.; Furukawa, H.; Lee, S.; Yaghi, O. M. J. Am. Chem. Soc. 2014, 136, 5271.

(23) Jiang, J.; Furukawa, H.; Zhang, Y.-B.; Yaghi, O. M. J. Am. Chem. Soc. 2016, 138, 10244.

(24) Li, B.; Wen, H.-M.; Wang, H.; Wu, H.; Tyagi, M.; Yildirim, T.; Zhou, W.; Chen, B. J. Am. Chem. Soc. 2014, 136, 6207. 